\title{
Prevalence of Refractive Errors and Accuracy of School-Based Visual Acuity Screening Programs Among School Children In Vietnam
}

\author{
Vu Tuan Anh \\ National Eye Centre \\ Fabrizio D'Esposito \\ The Fred Hollows Foundation \\ Le Thi Thanh Xuan ( $\sim$ lethithanhxuan@hmu.edu.vn ) \\ Institute for Preventive Medicine and Public Health, Hanoi Medical University \\ Pham Trong Van \\ Hanoi Medical University \\ Tran Thi Hoang Nga \\ National Eye Centre
}

\section{Research article}

Keywords: refractive errors, visual acuity screening programs, school children

Posted Date: May 5th, 2021

DOI: https://doi.org/10.21203/rs.3.rs-480579/v1

License: (1) (i) This work is licensed under a Creative Commons Attribution 4.0 International License.

Read Full License 


\section{Abstract \\ Background}

School-based visual acuity screening programs can help identify students with possible visual impairments, inform their parents of their status and the need for further examination and other conditions to assist students with visual impairments.

\section{Objectives}

This study aimed to calculate the prevalence of refractive errors among students and to describe the accuracy of visual acuity screening practices of school staff in some selected provinces in Viet Nam.

\section{Methods}

Visual acuity assessments were conducted by trained teachers and nurses at all schools participating in the survey, covering a sample size of 4,838 students. Around $30 \%$ of these students were then randomly selected for a close-up examination by ophthalmologists, making up a sub-sample of 1,404 students. The number of cases of low vision based on a set of criteria. The accuracy of visual acuity screening activities by comparing school staff's and ophthalmologists' results.

\section{Results}

The proportion of students with untreated eye problems and that of students with uncorrected refractive error are currently quite high (at respectively $18.52 \%$ and $24.64 \%$ ), especially in urban areas in Da Nang and Hai Duong provinces. Among every three children with refractive errors (RE), two of them have not received appropriate correction. The accuracy of the visual acuity screenings performed by teachers and school nurses in the project's target area is demonstrated by a sensitivity of $60.92 \%$ and a specificity of $93.76 \%$.

\section{Conclusions}

This indicates that efforts toward detecting school students with poor vision at school needs further investments to mitigate the current problems. This outcome suggests that teachers and school nurses need to be trained and equipped further with better skills and knowledge in conducting screening to improve their screening performance.

\section{Background}


Vietnam's National Prevention of Blindness Strategic Plan (2015-2020) identified refractive errors (RE) and childhood blindness as among key areas to be addressed to reduce the burden of avoidable blindness throughout the country. However, eye health has not been yet officially included in the school health curriculum. Besides, there is the lack of guidelines for implementing vision screening for students during annual school health checks. Additionally, there exists the shortcomings in the eye health awareness among students and teachers, as well as the lack of resources and training opportunities for school nurses and teachers to provide eye care and appropriate referrals (1).

The Fred Hollows Foundation (The Foundation) is a developmental organization aligned with Vietnam's Strategic Plan. The Foundation established the Vietnam Child Eye Care (VNCEC) and Better Eyes for Better Education (BEBE) projects. These two projects are piloted in three provinces Hai Duong, Da Nang and Tien Giang given these provinces are well equipped with eye health infrastructure and human resources by previous works of international non-governmental organisations.

School-based visual acuity screening programs can help identify students with possible visual impairments, inform their parents of their status and the need for further examination and other conditions to assist students with visual impairments (2),(3-5). Several developing countries have undertaken such studies on RE screening to determine the level of suitability of the programs in the school system as different countries have different infrastructure, systems and methods ,(6),(7). As the VNCEC project is targeting to reduce visual issues, including RE, among schoolchildren in Vietnam, it is critical that Vietnam has a similar study on school RE screening, which should focus on both primary and lower-secondary schoolchildren. This part aims to review RE screening practices of other programs in the world, especially developing countries and key issues to be noted in carrying out such programs.

Firstly, the cut-off points or a threshold for RE screening adopted may affect the cost and effectiveness of RE screening activities. Murthy (2000) suggests that it is possible to use the $<6 / 12$ (equivalent to $5 / 10$ ) in the better eye threshold to increase the cost effectiveness of the school program (8). Gianni et al argues that decreasing the cut-off point would lead to higher number of false negatives, which are the main cases to be avoided, and increasing the cut-off might lead to a larger number of false positive cases, which may affect the cost of the program (9). Secondly, the level of accuracy of the screenings conducted by school staff varies sharply in previous studies in the literature. In studies in Asian countries which adopted the $5 / 10$ (or equivalent) cut-off point, the level of sensitivity, which demonstrates the proportion of correctly identified positive cases among actual positive cases, could be as high as $93.5 \%$ in China (10) and as low as $59.0 \%$ (11) in Thailand. However, it can be noticed that there are few studies that examined the accuracy of RE screenings conducted on primary school students, and the studies involving these subjects tend to feature lower rates of accuracy, such as those done by Teerawattananon et al. (2014) and Ostadi Moghaddam et al. (2012) (11),(12). A study in Vietnam in Vung Tau presents a relatively high level of accuracy, at $86.7 \%$ sensitivity and $95.7 \%$ specificity, however without the participation of primary school students (13). Lastly, external factors such as parents' co-operation and training of school staff can have impacts on the implementation and effectiveness of such RE screening activities in school. In the study in 
Thailand, only 470 out of 624 students who were referred to ophthalmologists at provincial hospitals actually went there because of not obtaining consent from their parents or they did not show up (11).

There were only a few studies on the prevalence of RE in Vietnam, which mostly focus on adults and students in secondary schools in specific areas. In Ho Chi Minh City in 2009, Le Thi Thanh Xuyen et al. (2009) reported a very high rate of RE of $39.4 \%$, mostly consisting of myopia, among students in lower and upper-secondary schools (14). The authors also noticed a significantly higher prevalence of RE in urban areas compared with urban ones. In Ha Noi, in the same year, the rate of myopia was $33.7 \%$ (15).

Significantly, this rate rose to as high as $40.0 \%$ the urban area. In Vung Tau, Paudel et al. (2014) observed that the rate of RE was $21.5 \%$ on average, and $27.5 \%$ in urban areas (13). There was, however, a lack of studies that measure the prevalence of RE in other provinces, and especially among younger schoolchildren, including those in primary schools.

From the above literature review, it has pointed out that there is currently a lack of studies in Vietnam on the feasibility of school-based screenings for RE. There is an urgent need to address these gaps in the literature, especially in the context of Hai Duong, Da Nang and Tien Giang, given the fact that VNCEC and BEBE are being implemented in these provinces. The results of the study will serve as an input for the design of school eye health activities. This study would ultimately provide the rationale to inform the development of programmatic approaches and advocacy efforts. This baseline study's objectives are to identify the prevalence of RE among students as well as describe the accuracy of visual acuity screening practices of school staff in selected provinces.

\section{Materials And Methods}

\subsection{Study Design}

The baseline study covers two main components:

1. Visual acuity (VA) screening performed by teachers and school nurses (commonly referred to as school staff);

2. Follow-up RE screening performed by ophthalmologists;

\subsection{Study Setting}

As the VNCEC and BEBE projects are delivered in Hai Duong, Da Nang and Tien Giang, these three provinces were chosen for the study by The Foundation. The Foundation provided a list of schools participating in the projects, and a list of schools in the non-target area in Da Nang to Mekong Development Research Institute (MDRI). Based on this list, MDRI's sampling experts chose 26 schools in the target area of the projects, and 9 schools in the non-target area for the study.

As the ratio of the number of students in primary schools and lower-secondary schools participating in the project's area was around 1.2, school selection was done using the Probability Proportional to Size (PPS) approach, with the target of maintaining this ratio of students. Under this sampling approach, the schools 
with larger number of students were more likely to be chosen in the sample. The final number of schools chosen in the target area was 9 schools in Da Nang (comprising 5 primary schools), 9 schools in Tien Giang (comprising 6 primary schools), and 8 schools in Hai Duong (comprising 4 primary schools). In the non-target area in Da Nang, 9 schools were chosen, among which 5 were at the primary level.

\subsection{Participants and Recruitment}

With regards to VA screening by school staff and ophthalmologists, initially, students in all grades were selected to participate in this activity; however, during the first day of the fieldwork, The Foundation and MDRI realised that VA screening using alphabetical visual charts was not suitable for grade 1 students. Therefore, officially, only those from grade 2 to grade 9 took part in this part of the study.

\section{Recruitment Approach}

To ensure the representativeness of the survey, the multistage stratified sampling, Probability Proportional to Size sampling and random sampling techniques were used to select the sample. At first, the Probability Proportional to Size approach was used to select 26 target schools and 9 non-target schools, as discussed above in the Study Setting section. After the list of all classes and all students in selected school was available, the random sampling technique was used to identify one class per grade in each school, and all students from the selected class were chosen to participate in VA assessment. Among the students screened by school staff, $25 \%$ of them were randomly chosen to take part in a follow- up RE screening performed by ophthalmologists.

\section{Sample Size}

The sample size was estimated separately for the two groups: target and non-target. Visual acuity (VA) assessments were conducted by trained teachers and nurses at all schools participating in the survey, covering a sample size of 4,838 students. Around $30 \%$ of these students were then randomly selected for a close-up examination by ophthalmologists, making up a sub-sample of 1,404 students.

\subsection{Data Collection}

There is a variety of materials used in the baseline study to collect the data. Each component has its unique material and technique. In term of VA screening by school staff, we used training documents for nurses and other school staff on knowledge of RE and VA assessment procedure (Alphabetical) Visual chart Hard tape for measuring distance template to record VA screening result. We also refered to the supporting documents -VA screening guideline. Regarding to follow-up RE screening by ophthalmologis, we used (Alphabetical) Visual chart; Pinhole glasses and lens kit with trial lens set; Autorefractometer Ophthalmoscope; retinoscope Jackson Crossed Cylinder Auto lensmeter; Dilating eye drops; Template to record RE screening result. This is the initial list of equipment. During the implementation, due to the parents not approving the use of dilating eye drops, the ophthalmologists just screened for low VA and eye diseases and therefore utilised fewer materials. 


\subsection{Data Synthesis and Analysis}

Analysis of the prevalence of RE and visual issues

Based on ophthalmologists' results, the research team calculated the number of cases of low vision based on a set of criteria. Sampling weights were used to reflect the representativeness of the sample.

Some indicators for analysis as untreated vision problems (VA with current glasses of one or both eyes < $7 / 10$ or presenting eye diseases in one or both eyes), refractive error (Concluded as having RE in one or both eyes by ophthalmologists), uncorrected refractive error (Concluded as having RE in one or both eyes by ophthalmologists and VA with current glasses of one or both eyes $<7 / 10$ ), corrected refractive error (Concluded as having RE in one or both eyes by ophthalmologists and VA with current glasses of both eyes $>=7 / 10$ ), mild cases of refractive error (that do not require correction) (Concluded as having RE in one or both eyes by ophthalmologists and VA without glasses of both eyes $>=7 / 10$ ).

Untreated vision problems was defined as VA with current glasses of one or both eyes $<7 / 10$ or presenting eye diseases in one or both eyes

Analysis of school staff's performance

The research team assessed the accuracy of VA screening activities by comparing school staff's and ophthalmologists' results. From ophthalmologists' results, the students who were concluded by ophthalmologists as having a vision of lower than 7/10 in either eyes (with current pair of glasses, if they already had one), or having abnormalities in either eyes, were marked as those with "positive" results. From school staff's results, the research team based solely on their final column in the result forms (about whether the student was referred for further examination) to identify those with "positive" results. This was because the study is more interested in the accuracy of the referrals that school staff made than their detailed VA results.

School staff's results were then compared to those of ophthalmologists by a set of indicators, consisting of sensitivity, specificity, positive predictive value and negative predictive value. Sensitivity was calculated as the ability of school staff to identify low VA (The proportion of actual cases of low VA that are correctly identified by school staff). Meanwhile, specificity was analysed as The ability of school staff to identify normal VA (The proportion of actual cases of normal VA that are correctly by school staff).

\subsection{Ethical and other Approvals Obtained}

An ethical approval application was lodged to the Ethical Review Board of the Hanoi Medical University Ref No. 57/HDDDDHYHN in early December 2016. The application was assessed through a full review procedure and was approved in late January 2017. The survey was also approved by the Project Management Board in the Department of Education of Training at each of the three provinces. The Department in each province also provided strong support to arrange logistics, in order to help the 
enumerators to approach the schools more easily. Consent forms were sent to parents of students participating in the examination. The study was only conducted with children's parent consent agreement.

\section{Results}

\section{Prevalence of RE and visual issues}

As demonstrated in Table 3.1, the overall prevalence of RE was $24.64 \%$ in the target area, of this, $17.94 \%$ were corrected, $11.54 \%$ were mild cases, and $70.53 \%$ were uncorrected cases. RE affected $32.65 \%$ of the student population in the non-target districts of Da Nang, $44.27 \%$ of those in Da Nang's targeted districts, $35.60 \%$ of those in Hai Duong and only $6.42 \%$ of students in the project's target areas in Tien Giang, where the prevalence of RE was the lowest.

Breaking down these results by classification criteria also revealed some interesting trends. There was no proven difference between male and female students in terms of eye diseases and RE, however, there was a significant difference (at $99 \%$ of confidence) of $27.59 \%$ in the prevalence of RE (in one or both eyes) in rural $(14.26 \%)$ compared to urban $(41.85 \%)$ areas, proving once again a well-observed fact in the eye care community. In addition, lower-secondary students were more likely to have untreated eye diseases and RE than their primary counterparts (at $99 \%$ of confidence).

While there were several notable differences in the prevalence of eye issues and RE between provinces, area types and school levels, there was no striking difference in terms of corrected, mild or uncorrected RE proportions across those classification criteria. The general trend was that only 15 to $20 \%$ of RE cases have been corrected, together with around $10 \%$ of mild cases requiring no treatment and leaving behind $60 \%$ to $70 \%$ of uncorrected cases.

It has also been shown from the results that the prevalence of untreated vision problems (including RE) in one or both eyes varies among areas. Specifically, Tien Giang had a significantly lower proportion of untreated cases of visual issues (around $4.49 \%$ ) than in other provinces. The non-target area in Da Nang also showed a lower level of prevalence compared to the targeted area in the same province $(23.66 \%$ compared to $31.94 \%$, verified by a t-test at $95 \%$ of confidence). Meanwhile, there were no statistically significant difference between the target areas in Da Nang and Hai Duong. The average prevalence of untreated eye issues was around 28 to $32 \%$ of in these two areas.

\section{Table 1. Prevalence of untreated vision problems and RE by province and project area}




\begin{tabular}{|c|c|c|c|c|c|c|}
\hline & & $\begin{array}{l}\text { Untreated vision } \\
\text { problems } \\
\text { (including RE) } \\
\text { (\%) }\end{array}$ & $\begin{array}{l}\text { RE in general } \\
\text { (including } \\
\text { corrected cases) } \\
(\%)\end{array}$ & $\begin{array}{l}\text { Uncorrected } \\
\text { RE (\%) }\end{array}$ & $\begin{array}{l}\text { Corrected } \\
\text { RE (\%) }\end{array}$ & $\begin{array}{l}\text { Mild RE } \\
\text { that do } \\
\text { not } \\
\text { require } \\
\text { correction } \\
(\%)\end{array}$ \\
\hline \multirow{4}{*}{$\begin{array}{l}\text { Da Nang } \\
\text { (Non- } \\
\text { target) }\end{array}$} & $\mathrm{n}$ & 303 & 303 & 98 & 98 & 98 \\
\hline & $\%$ & 23.66 & 32.65 & 72.46 & 15.21 & 12.33 \\
\hline & $\begin{array}{l}\text { Cl95\% } \\
\text { low } \\
\text { (L) }\end{array}$ & 18.85 & 27.34 & 63.45 & 7.98 & 5.70 \\
\hline & $\begin{array}{l}\mathrm{Cl} 95 \% \\
\text { up (U) }\end{array}$ & 28.47 & 37.96 & 81.46 & 22.45 & 18.96 \\
\hline \multirow{4}{*}{$\begin{array}{l}\text { Total } \\
\text { (Target } \\
\text { only) }\end{array}$} & $\mathrm{n}$ & 1039 & 1039 & 325 & 325 & 325 \\
\hline & $\%$ & 18.52 & 24.64 & 70.53 & 17.94 & 11.54 \\
\hline & $\begin{array}{l}\mathrm{Cl} 95 \% \\
\mathrm{~L}\end{array}$ & 16.16 & 22.02 & 65.54 & 13.74 & 8.05 \\
\hline & $\mathrm{Ul}^{\mathrm{Cl} 95 \%}$ & 20.89 & 27.27 & 75.51 & 22.13 & 15.03 \\
\hline \multicolumn{7}{|c|}{ By location (Target only) } \\
\hline \multirow[t]{4}{*}{ Da Nang } & $\mathrm{n}$ & 390 & 390 & 183 & 183 & 183 \\
\hline & $\%$ & 31.94 & 44.27 & 70.56 & 14.92 & 14.52 \\
\hline & $\begin{array}{l}\mathrm{Cl} 95 \% \\
\mathrm{~L}\end{array}$ & 27.29 & 39.32 & 63.90 & 9.71 & 9.36 \\
\hline & $U^{\mathrm{Cl} 95 \%}$ & 36.58 & 49.23 & 77.23 & 20.13 & 19.67 \\
\hline \multirow{4}{*}{$\begin{array}{l}\text { Hai } \\
\text { Duong }\end{array}$} & $\mathrm{n}$ & 297 & 297 & 122 & 122 & 122 \\
\hline & $\%$ & 28.57 & 35.60 & 70.64 & 19.00 & 10.35 \\
\hline & $\begin{array}{l}\mathrm{Cl} 95 \% \\
\mathrm{~L}\end{array}$ & 23.40 & 30.13 & 62.45 & 11.94 & 4.87 \\
\hline & $\mathrm{U}^{\mathrm{Cl} 95 \%}$ & 33.74 & 41.08 & 78.84 & 26.06 & 15.83 \\
\hline \multirow[t]{3}{*}{ TienGiang } & $\mathrm{n}$ & 352 & 352 & 20 & 20 & 20 \\
\hline & $\%$ & 4.49 & 6.42 & 69.97 & 26.42 & 3.61 \\
\hline & $\begin{array}{l}\mathrm{Cl} 95 \% \\
\mathrm{~L}\end{array}$ & 2.32 & 3.85 & 47.96 & 5.25 & -5.35 \\
\hline
\end{tabular}



$\mathrm{Cl} 195 \%$
6.67
8.99
91.98
47.60
12.56

Performance of school staff in conducting VA assessment

The performance of school staff plays a key role in the effectiveness of school eye health intervention because their initial stage of VA screening will help determine the students who need further examination by ophthalmologists. It is important to maximise correctly specified positive cases and avoid false negative cases as these would be against both the students' and the project's interests.

Table 2 below shows some diagnostic statistics demonstrating the accuracy of VA screening performed by school staff. Target and non-target areas are separated and the "Total" value only considers target areas as some interventions have only been undertaken there.

Table 2. Performance of school staff by location

\begin{tabular}{|c|c|c|c|c|c|}
\hline & & Sensitivity (\%) & Specificity (\%) & PPV (\%) & NPV (\%) \\
\hline \multirow[t]{3}{*}{ Da Nang (Non-target) } & $\%$ & 69.01 & 90.09 & 68.06 & 90.48 \\
\hline & Cl95\% L & 57.99 & 86.21 & 57.02 & 86.66 \\
\hline & $\mathrm{Cl} 95 \% \mathrm{U}$ & 80.04 & 93.96 & 79.09 & 94.29 \\
\hline \multirow[t]{3}{*}{ Total (Target only) } & $\%$ & 60.92 & 93.76 & 74.36 & 88.98 \\
\hline & CI95\% L & 54.68 & 92.08 & 68.18 & 86.86 \\
\hline & Cl95\% U & 67.17 & 95.44 & 80.54 & 91.10 \\
\hline \multicolumn{6}{|l|}{ Bylocation(Target only) } \\
\hline \multirow[t]{3}{*}{ Da Nang } & $\%$ & 56.06 & 92.64 & 79.57 & 80.47 \\
\hline & Cl95\% L & 47.48 & 89.43 & 71.22 & 75.94 \\
\hline & Cl95\% U & 64.64 & 95.84 & 87.92 & 85.01 \\
\hline \multirow[t]{3}{*}{ Hai Duong } & $\%$ & 65.59 & 89.71 & 74.39 & 85.12 \\
\hline & Cl95\% L & 55.75 & 85.50 & 64.74 & 80.32 \\
\hline & Cl95\% U & 75.43 & 93.91 & 84.04 & 89.91 \\
\hline \multirow[t]{3}{*}{ TienGiang } & $\%$ & 76.92 & 97.05 & 50.00 & 99.10 \\
\hline & Cl95\% L & 50.42 & 95.24 & 25.99 & 98.07 \\
\hline & Cl95\% U & 103.42 & 98.86 & 74.01 & 100.12 \\
\hline
\end{tabular}

In the target area, school staff's overall performance was reflected by a sensitivity measure of $60.92 \%$. It means that only $60.92 \%$ of students with either eye abnormalities or whose vision was lower than $7 / 10$ in 
one or both eyes were identified by school staff. The specificity level demonstrated that $93.76 \%$ of students with good vision were recognised by school staff, leaving a false positive rate of approximately $6.24 \%$. Among the students who were referred to ophthalmologists, $74.36 \%$ were actual cases of low vision (as shown in the positive predictive value). This means that ophthalmologists would need to spend extra time and efforts on the $25.64 \%$ of students who were incorrectly referred to them.

In the non-target area in Da Nang, the sensitivity, specificity, positive predictive and negative predictive values were respectively $69.01 \%, 90.09 \%, 68.06 \%$ and $90.48 \%$. In comparison with those of the target area in the same province, these statistics demonstrated a better coverage of correct referrals, however they also indicated a slightly higher level of false positive cases, as shown by a lower specificity measure.

Across the surveyed provinces in the target areas, Hai Duong performed significantly better than Da Nang in terms of sensitivity, with $9.53 \%$ more cases of low vision being identified. Between Tien Giang and two other provinces, although the sensitivity measure seems to be higher, statistical tests proved that they only featured a significantly higher level of specificity, lower level of positive predictive value and higher level of negative predictive value, without any firm evidence backing the difference in sensitivity. These did not mean that school staff in Tien Giang performed better, but were most likely the results of the low prevalence of low vision and RE in Tien Giang.

Statistically significant differences have been revealed between urban and rural areas. Statistical test results had demonstrated that in rural areas, school staffs were better at identifying low vision, with a sensitivity measure of $74.00 \%$, compared to $57.45 \%$ in urban areas. Their positive predictive value was also significantly lower and they also demonstrated a higher negative predictive value. This implied that rural school staff had fewer cases of false negative results.

\section{Discussion}

This part discusses the results of VA screenings, including figuring out the proportion of school children with untreated vision problems, uncorrected RE and corrected RE in the surveyed areas and assessing the accuracy of VA screening at the school level. Regarding the prevalence of presenting low VA and RE among school children, the results of this study confirm previously investigated trends in surveys in other Vietnamese locations. The accuracy of school staff's screening activities, however, is lower than previously observed in other provinces, with some noticeable differences across location and area type.

Compared to some studies in Vietnam, the rates of RE in this study are considerably consistent. Le Thi Thanh Xuyen et al. (2009) reported that the rate of RE in Ho Chi Minh City was 39.35\% (14), with a notable difference between rural and urban areas. Vu Thi Thanh et al. (2009) also concluded a myopia rate of $33.7 \%$ in $\mathrm{Ha}$ Noi, with the figures rising above $40 \%$ in central urban districts (15). In Vung Tau, Paudel et al. (2014) observed an overall rate of RE of $21.5 \%$, more specifically $27.5 \%$ in the urban area, but just focusing on lower-secondary schools. This study's results regarding the prevalence of RE in Da Nang (44.27\%), Hai Duong (35.60\%) and Tien Giang (6.42\%) can be considered consistent, with an overall rate of $24.64 \%$ in all three provinces (13). Discrepancies between these provinces can be due to the unbalanced proportion of 
rural and urban schools, as well as of primary and lower-secondary schools among them. Specifically, all schools in Da Nang's target area are urban schools while most of the schools in Tien Giang are located in rural areas.

A limitation of this study is that due to parents' disapproval with the ophthalmologists' use of dilating eye drops when conducting eye examination at the schools, students' specific RE condition (myopia, hyperopia or astigmatism) was not collected. Instead, the ophthalmologists examined the students' VA like the school staff did to assess their accuracy. If any abnormalities were noticed, a result form has been sent to the parents to inform them so they can have their child further checked by an eye specialist. Therefore, without such information, comparison with existing studies in terms of each condition is not possible.

In terms of school staff's performance, the overall performance in the target area is much weaker than previously reported by Paudel et al. (2014) in Vung Tau, where the accuracy is observed at $86.7 \%$ sensitivity, $95.7 \%$ specificity, $86.7 \%$ positive predictive value and $95.7 \%$ negative predictive value (13). When compared to studies in other Asian countries (Table 3.2.3), the sensitivity and specificity measures in this study are only higher than those of Iran. Nevertheless, those studies mostly approached secondary school students. When it comes to screening primary school children's VA, most previous studies feature lower detection rates.

\section{Table 3. Comparison of VA screening results with other studies}




\begin{tabular}{|c|c|c|c|c|}
\hline Location & Author & Cut-off & School level & Results \\
\hline China & $\begin{array}{l}\text { Sharma et al. (2008) } \\
\text { (10) }\end{array}$ & $\begin{array}{l}\leq 20 / 40 \\
(5 / 10)\end{array}$ & Secondary & $\begin{array}{l}\text { Sensitivity } 93.5 \% \\
\text { Specificity } 91.2 \%\end{array}$ \\
\hline Iran & $\begin{array}{l}\text { Khandekar et al. } \\
(2009)(16)\end{array}$ & $<20 / 40(6 / 12)$ & $\begin{array}{l}\text { Children aged } 3- \\
6 \text { years }\end{array}$ & $\begin{array}{l}\text { Sensitivity } \\
74.5 \% \text { Specificity } \\
97.2 \%\end{array}$ \\
\hline Nigeria & $\begin{array}{l}\text { Tabansi et al. } \\
(2009)(17)\end{array}$ & $\begin{array}{l}<6 / 18 \text { in either } \\
\text { or both eyes }\end{array}$ & $\begin{array}{l}\text { Children aged 6- } \\
11 \text { years }\end{array}$ & $\begin{array}{l}\text { Sensitivity } \\
53.3 \% \text { Specificity } \\
98.4 \%\end{array}$ \\
\hline Nepal & $\begin{array}{l}\text { Adhikari\&Shrestha, } \\
(2011)(18)\end{array}$ & $<6 / 12$ & $\begin{array}{l}\text { Children aged } 3- \\
7 \text { years }\end{array}$ & $\begin{array}{l}\text { Sensitivity } \\
80.0 \% \text { Specificity } \\
99.0 \%\end{array}$ \\
\hline Iran & $\begin{array}{l}\text { Ostadi Moghaddam } \\
\text { et al (2012) (12) }\end{array}$ & $\begin{array}{l}\leq 20 / 25 \\
(8 / 10)\end{array}$ & $\begin{array}{l}\text { Both primary and } \\
\text { secondary }\end{array}$ & $\begin{array}{l}\text { Sensitivity } 37.5 \% \\
\text { Specificity } 92 \%\end{array}$ \\
\hline India & $\begin{array}{l}\text { Rewri et al., (2013) } \\
\text { (19) }\end{array}$ & $\leq 6 / 12$ & $\begin{array}{l}\text { Children aged } \\
10-19 \text { years }\end{array}$ & $\begin{array}{l}\text { Sensitivity } 96.2 \% \\
\text { Specificity } 90.2 \%\end{array}$ \\
\hline Peru & $\begin{array}{l}\text { Latorre-Arteaga et al., } \\
(2014)(20)\end{array}$ & $\begin{array}{l}\leq 6 / 9 \text { in one or } \\
\text { both eyes }\end{array}$ & $\begin{array}{l}\text { Children aged 3- } \\
11 \text { years and }\end{array}$ & $\begin{array}{l}\text { Sensitivity } 93.0 \% \\
\text { Specificity } 47.8 \%\end{array}$ \\
\hline Thailand & $\begin{array}{l}\text { Teerawattananon et } \\
\text { al. (2014) (11) }\end{array}$ & $\begin{array}{l}\leq 20 / 40 \\
(5 / 10)\end{array}$ & Primary & $\begin{array}{l}\text { Sensitivity } 59 \% \\
\text { Specificity } 98 \%\end{array}$ \\
\hline $\begin{array}{l}\text { Vung Tau - } \\
\text { Vietnam }\end{array}$ & $\begin{array}{l}\text { Paudel et al. (2014) } \\
\text { (13) }\end{array}$ & $\begin{array}{l}\leq 20 / 40 \\
(5 / 10)\end{array}$ & Secondary & $\begin{array}{l}\text { Sensitivity } 86.7 \% \\
\text { Specificity } 95.7 \%\end{array}$ \\
\hline India & $\begin{array}{l}\text { Priya et al., } \\
(2015)(21)\end{array}$ & $<20 / 30$ & $\begin{array}{l}\text { Children aged 6- } \\
17 \text { years }\end{array}$ & $\begin{array}{l}\text { Sensitivity } \\
79.2 \% \\
\text { Specificity } \\
93.3 \%\end{array}$ \\
\hline India & $\begin{array}{l}\text { Saxena et al., (2015) } \\
\text { (22) }\end{array}$ & $<6 / 12$ & $\begin{array}{l}\text { Children aged 6- } \\
15 \text { years }\end{array}$ & $\begin{array}{l}\text { Sensitivity } \\
77.0 \% \\
\text { Specificity } \\
97.1 \%\end{array}$ \\
\hline
\end{tabular}




\begin{tabular}{|lllll|}
\hline India & Kaur et al., & $<6 / 9$ in either & Children aged $\leq$ & Sensitivity \\
& (2016) (23) & & & $98.0 \%$ \\
& & & Specificity \\
& & & $27.8 \%$ \\
\hline This study & & & Both primary and & Sensitivity $60.9 \%$ \\
& & & Specificity $93.8 \%$ \\
\hline
\end{tabular}

One factor affecting the screening performance of school staff which has not been frequently discussed is the quality of the training given to them. Paudel et al. (2014) only mentioned that they conducted a halfday training session with practice and provision of necessary equipment (13). This is very similar with the training sessions that were held at the three provinces before the field work of this study. However, it has been noticed during The Foundation and MDRI's supervision that the school staff (especially in Da Nang's target area) were initially not very confident when implementing VA screening at their schools, and were not clear about how to record results on the VA form. This was improved by The Foundation and MDRI in the survey in the non-target area by providing school staff more time to practice before the field work. That might explain why school staff in the non-target area performed significantly better than their colleagues in targeted schools.

The fact that school staff in rural areas performed significantly better than those in urban schools might be attributed to two factors. Firstly, in rural areas, eye issues are less prevalent, and thus school staff had more time to examine the students who showed signs of low vision. In urban areas, with a high rate of untreated visual issues at around $30 \%$, school staff's attention was more diverted. In addition, teachers could only conduct VA screening during a fixed amount of time allocated for this activity in the timetable and very few schools allowed extra time. This fixed amount of time and the large proportion of students with low vision might have affected the quality of their screening activities.

A small number of unidentified cases of eye problems ( $8 / 118$ - in the whole target and non-target sample) such as conjunctivitis, blepharitis, conjunctiva stones and retinal detachment were encountered by school staff. They were often overlooked as school staff have not been trained to identify such abnormalities. Although the proportion of students with these diseases is small, the project may consider training school staff on identifying these abnormalities and how to correctly refer these students for treatment.

\section{Limitations}

This baseline study has some limitations. First is the disagreement of the parents with the use of dilating eye drops in visual acuity assessment. Second is the waiting time between the teacher's assessment and doctor's follow-up examination. Specifically, ophthalmologists are unable to conduct the eye examinations thoroughly as permission has not been granted by parents for the use of dilating eye drops on the children, although the research team has tried to convince them. However, as the safety of the children and the cooperation of the parents are highly valued by the research team, the research's design has been modified 
to remove this component. The children identified as having visual issues by teachers and confirmed by ophthalmologists have therefore been referred to local hospitals for further examination. This has in turn made this study unable to analyse in more detailed indicators for various forms of RE. In addition, visual acuity screenings performed by school staff and doctors take place in separate days for most schools. This may lead to inconsistencies in the evaluation of students' visual acuity between two days of screening, especially when the eyes of children possess great adjustment capacity during school age.

\section{Conclusions}

The proportion of students with untreated eye problems and that of students with uncorrected refractive error are currently quite high (at respectively $18.52 \%$ and $24.64 \%$ ), especially in urban areas in Da Nang and Hai Duong provinces. The accuracy of the visual acuity screenings performed by teachers and school nurses in the project's target area is demonstrated by a sensitivity of $60.92 \%$ and a specificity of $93.76 \%$. This indicates that efforts toward detecting school students with poor vision at school needs further investments to mitigate the current problems. This outcome suggests that teachers and school nurses need to be trained and equipped further with better skills and knowledge in conducting screening to improve their screening performance.

\section{Declarations}

Funding: This research received no external funding.

Acknowledgements: This survey is a project supported by funding from Standard Chartered Bank via The Fred Hollows Foundation. The information and opinions contained in it do not necessarily reflect the views or policy of either Standard Chartered Bank or The Fred Hollows Foundation. We are also grateful to the Project Management Board of the School Eye Heath projects, as well as 35 primary and lower-secondary schools in Hai Duong, Da Nang and Tien Giang for their strong support during the project's field work. We owe thanks to the great team of senior ophthalmologists from Hai Duong Hospital of Ophthalmology and Dermatology, Da Dang Hospital of Ophthalmology and Tien Giang Hospital of Ophthalmology for providing a thorough training to 175 teachers and school nurses in the three provinces, and for conducting visual acuity tests for over 1,400 students. Last but not least, the implementation of this project would not have been possible without the contribution of 12 enthusiastic enumerators whose professional experience has helped ensure that our collected data is truthful and always of the highest quality.

CompetingInterest: The authors declare no conflict of interest.

Ethics approval: Subjects were adequately informed about the purpose of the study and participated voluntarily. Information on the study subjects is confidential and data collected in this study were only used for research purposes. The study did not affect the rights, health, and economy of the study subjects.

Consent to participate: Verbal informed consent was obtained prior to the interview.

Consent for publication: Not applicable

Page 14/16 
Availability of data: Data are available from corresponding author upon reasonable request.

Code availability: Not applicable

Author Contributions: Conceptualization, A.V.T, F.D, V.P.T, N.T.H.T.; data curation, X.T.T.L., A.V.T, F.D, V.P.T, N.T.H.T; formal analysis, X.T.T.L., A.V.T, V.P.T.; investigation, A.V.T, V.P.T, N.T.H.T., X.T.T.L.; methodology, X.T.T.L., A.V.T, F.D, V.P.T, N.T.H.T.; project administration and supervision, A.V.T, N.T.H.T.; visualization, X.T.T.L., A.V.T; writing-original draft, A.V.T, X.T.T.L.; writing, reviewing \& editing, A.V.T, F.D, X.T.T.L., V.P.T, N.T.H.T. All authors commented on previous versions of the manuscript. All authors read and approved the final manuscript.

\section{References}

1. WHO. Universal Eye Health: A Global Action Plan 2014-2019. 2013. http://www.who.int/blindness/actionplan/en/. Accessed 11 Apr 2018.

2. Agarwal R, Dhoble P. Study of the Knowledge, Attitude and Practices of Refractive Error with Emphasis on Spectacle Usages in Students of Rural Central India. Journal of Biomedical and Pharmaceutical Research. 2013; 2(3):150-4.

3. Holguin AM, Congdon N, Patel N, et al. Factors Associated with Spectacle-Wear Compliance in SchoolAged Mexican Children. Investigative Opthalmology\& Visual Science Invest. Ophthalmol. Vis. Sci. 2006; 47(3):925. doi:doi:10.1167/iovs.05-0895

4. Alrasheed SH, Naidoo KS, Clarke-Farr PC. Childhood eye care services in South Darfur State of Sudan: Learner and parent perspectives. African Vision and Eye Health. 2016; 75(1). doi:doi:10.4102/aveh.v75i1.315

5. Horwood AM. Compliance with first time spectacle wear in children under eight years of age. Eye. 1998; 12(2):173-8. doi:doi:10.1038/eye.1998.43

6. Ormsby GM, Arnold A, Busija L, Mörchen M, Bonn TS, Keeffe JE. The Impact of Knowledge and Attitudes on Access to Eye-Care Services in Cambodia. Asia-Pacific Journal of Ophthalmology. 2012; 1(6):331-5. doi:doi:10.1097/apo.0b013e31826d9e06

7. Takeo Eye Hospital. Knowledge, Attitudes and Practice (KAP) Survey - 2010. Retrieved from Takeo Eye Hospital website: http://www.teh.caritascambodia.org/tehdocs/event\%20pdf/Takeo_Province_KAP_FINAL_REPORT.pdf. 2010.

8. Murthy GVS. Vision testing for Refractive Errors in Schools. Community Eye Health. 2000; 13(13):3-5.

9. Gianini RJ, Masi E, Coelho EC, Oréfice FR, Moraes RA. Prevalence of low visual acuity in public school's students from Brazil. Rev SáudePública. 2004; 38(2).

10. Sharma A, Li L, Song Y, et al. Strategies to improve the accuracy of vision measurement by teachers in rural Chinese secondary schoolchildren: Xichang Pediatric Refractive Error Study (X-PRES) report no. 6. Archives of ophthalmology. 2008; 126(10):1434-40. 
11. Teerawattananon K, Myint CY, Wongkittirux K, et al. Assessing the accuracy and feasibility of a refractive error screening program conducted by school teachers in pre-primary and primary schools in Thailand. PloS one. 2014; 9(6):e96684.

12. Ostadi Moghaddam $\mathrm{H}$, Fotouhi $\mathrm{A}$, Hashemi $\mathrm{H}$, et al. Validity of vision screening tests by teachers among school children in Mashhad, Iran. Ophthalmic epidemiology. 2012; 19(3):166-71.

13. Paudel $P$, Ramson $P$, Naduvilath $T$, et al. Prevalence of vision impairment and refractive error in school children in Ba Ria-Vung Tau province, Vietnam. Clinical \& experimental ophthalmology. 2014; 42(3):217-26.

14. Le Thi Thanh Xuyen, Bui Thi Thu Huong, Phi Duy Tien, et al. Prevalence of Refractive error and Knowledge, Attitudes and Self Care Practices Associated with Refractive Error in Ho Chi Minh City. Journal of Ho Chi Minh Medicine. 2009; 13(1):13-25.

15. Vu Thi Thanh, Doan Duy Hau, Hoang Thi Phuc. Study on characteristics of school myopia in Hanoi primary and secondary school students in 2009. Journal of practical medicine. 2009; 905:92-4.

16. Khandekar R, Parast N, Arabi A. Evaluation of 'vision screening' program for three to six-year-old children in the Republic of Iran. Indian J Ophthalmol. 2009; 57(6):437-42. doi:10.4103/03014738.57151

17. Tabansi P.N., Anochie I.C., Nkanginieme K.E., Pedro-Egbe C.N. Evaluation of teachers' performance of vision screening in primary school children in Port Harcourt. Niger J Ophthalmol. 2009; 17(1):27-31. doi:10.4314/njo.v17i1.46759

18. Adhikari S., Shrestha U. Validation of performance of certified medical assistants in preschool vision screening examination. Nepal J Ophthalmol. 2011;3(2):128-33. doi:10.3126/nepjoph.v3i2.5264

19. Rewri P., Kakkar M., Raghav D. Self-vision testing and intervention seeking behavior among school children: a pilot study. Ophthalmic epidemiology. 2013; 20(5):315-20. doi:10.3109/09286586.2013.823506

20. Latorre-Arteaga S, Gil-González D, Enciso O, Phelan A, García-Muñoz A, Kohler J. Reducing visual deficits caused by refractive errors in school and preschool children: results of a pilot school program in the Andean region of Apurimac, Peru. Glob Health Action. 2014; 7(1):22656.

doi:10.3402/gha.v7.22656

21. Priya A, Veena K, Thulasiraj R, Fredrick M, Venkatesh R, Sengupta S. Vision screening by teachers in southern Indian schools: testing a new "all class teacher" model. Ophthalmic epidemiology. 2015; 22(1):60-5. doi:10.3109/09286586.2014.988877

22. Saxena R, Vashist P, Tandon R, Pandey RM, Bhardawaj A, Menon V. Accuracy of visual assessment by school teachers in school eye screening program in delhi. Indian J Community Med. 2015; 40(1):3842. doi:10.4103/0970-0218.149269

23. Kaur G, Koshy J, Thomas S, Kapoor H, Zachariah JG, Bedi S. Vision screening of school children by teachers as a community based strategy to address the challenges of childhood blindness. $J$ ClinDiagn Res. 2016; 10(4):NC09-14. . 